\title{
Uma questão de sal do cotidiano: literatura, boemia e trabalho em Antísthenes Pinto
}

\author{
Vinicius Alves do Amaral*
}

Resumo: O romance Os Agachados, de Antísthenes Pinto, aborda a boemia amazonense de um ponto de vista aparentemente óbvio. Contudo, para um pesquisador atento ele pode ajudar a compreender as tensões existentes entre a intelectualidade e os mundos do trabalho na Manaus da década de 1980. Utilizando-se da contribuição de Pierre Bourdieu sobre habitus e campo intelectual e de Edward Palmer Thompson sobre a economia moral da multidão, pretendo analisar as principais transformações da capital amazonense por meio dessa obra.

Palavras-chave: literatura; boemia; Manaus.

Abstract: The novel The Crouched by Antísthenes Pinto approaches the Amazonian bohemian from an apparently obvious point of view. However, for an attentive researcher he can help to understand the tensions between the intelligentsia and the worlds of work in the Manaus of the 1980s. Using Pierre Bourdieu's contribution on habitus and intellectual field and Edward Palmer Thompson on economics morality of the crowd, I intend to analyze the main transformations of the Amazonian capital through this work.

Keywords: literature; bohemia; Manaus.

O escritor amazonense Antísthenes Pinto em um dos muitos versos de Curvas do Tempo (1984) ataca a erudição, "palavra que choca pela sua pungente ancianidade", e seus maiores cultores, os intelectuais. Ecoando Alberto Caeiro, ele afirma:

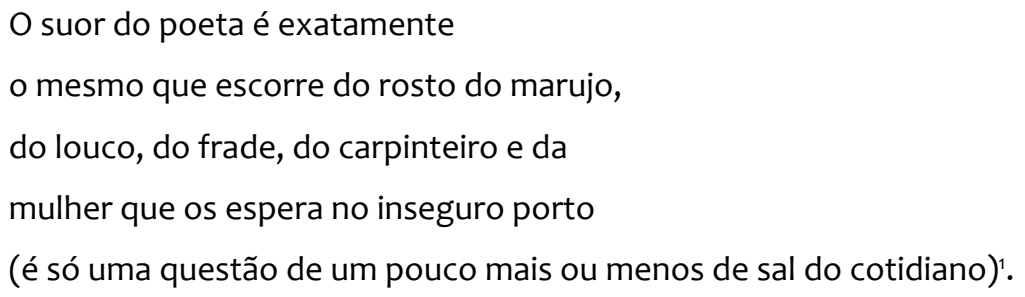

Doutorando em História pela Universidade Federal Fluminense (UFF). Mestre em História Social pela Universidade Federal do Amazonas (UFAM).E-mail: viniciuscarqueija@gmail.com.

1 PINTO, Antísthenes. Curvas do Tempo. Manaus: ed. autor, 1984, p. 28-29, 
O que o autor problematiza é a aura excepcional que cerca o poeta. Aura construída historicamente: Angel Rama, em ensaio antológico, assinala que o domínio da palavra escrita conferia um status especial, principalmente em meio à grande imensidão do continente americano que cultivava a oralidade como forma de expressão.

Os signos apareciam como obra do Espírito e os espíritos conversavam entre si graças a eles. Obviamente se tratava de funções culturais das estruturas de poder, cujas bases reais poderíamos elucidar, mas não foram assim concebidas, nem percebidas, nem assim foram vividas por seus integrantes. ${ }^{2}$

Nesse contexto, por um bom tempo a poesia foi uma arte quase divinatória, reservada a meia dúzia de homens ligados à administração colonial e posteriormente nacional. Devido à restrição da escrita, o consumidor e o produtor literário se confundiam. A expansão do letramento alterou o painel consideravelmente: as letras transformaram-se em alavanca social para classes emergentes e, em reação a esse movimento, grupos sociais abastados procuram reforçar seu espaço cultuando os aspectos mais técnicos da linguagem (portanto, o surgimento de academias literárias pela América Latina entre meados do século XIX e XX está associado à propagação das redes de ensino e à discussão pedagógica). ${ }^{3}$

Mas outro processo também contribuiu para as primeiras rachaduras na imagem "clerical" do escritor: o desenvolvimento da imprensa. Os articulistas e mesmo propagandistas são recrutados em meio aos devotos da literatura. Para Sérgio Miceli, a imprensa profissionalizou o escritor: escrevendo diariamente e ganhando pelo que publica, a literatura aos poucos era encarada como algo entre o hobby e o trabalho. ${ }^{4}$ No entanto, a aura excepcional do demiurgo perdurava.

Mesmo na obra de Antísthenes Pinto, tais reminiscências são perceptíveis, especialmente no seu romance mais profano, Os Agachados (1985). O enredo gira em torno de Rinaldo, intelectual e político de oposição, que frequenta os muitos bares de Manaus, interagindo com personagens fictícios e reais, enquanto é assombrado por visões do passado.

Em Os Agachados, o autor novamente coloca em questão o sal do cotidiano; contudo, dessa vez ele conjuga de forma muito mais intricada a realidade e a imaginação. O romance pode ser lido como uma fonte preciosa não só sobre a boemia (como foi definido de forma mais óbvia pelos críticos da época), mas também sobre as transformações pelas quais a cidade vinha passando naquele contexto. Pretendo no presente artigo explorar essa última faceta da obra, analisando os vínculos entre os intelectuais e os trabalhadores em Manaus.

\section{Questões preliminares}

Por um bom tempo, a história do Amazonas foi uma galeria de "homens de fidalguia excepcional" (em sua maioria, conquistadores ou administradores empenhados em vencer a "natureza hostil"), na qual eventualmente algum indígena entrava de

\footnotetext{
RAMA, Angel. A cidade das letras. Trad. Emir Sader. São Paulo: Brasiliense, 1985, p. 43.

RAMA. A cidade e as letras, p. 86.

MICELI, Sérgio. Intelectuais à brasileira. São Paulo: Companhia das Letras, 2001, p. 54.
} 
penetra (como o rebelde Ajuricaba5). Justificava-se a restrição dos personagens somente aos elementos oriundos do Estado, seja português ou brasileiro, com o argumento de que as únicas fontes históricas eram os documentos oficiais.

Evidente que os praticantes dessa historiografia eram devedores de uma concepção do conhecimento histórico vinculada à formação dos estados nacionais e ao desejo de inserir a disciplina entre as ciências. Contudo, os pesquisadores atuais são guiados por outro paradigma, esse mais crítico em relação à objetividade histórica e mais comprometido com os sujeitos sociais até então negligenciados.

Dentre as muitas correntes que surgiram na segunda metade do século $\mathrm{XX}$, a História Social tem se destacado pela forma como dialoga com as exigências desse novo paradigma, especialmente por meio dos estudos de Edward Thompson, Eric Hobsbawm e Raphael Samuel. Para os desejosos de uma definição extremamente pontual sobre a História Social praticada por esses autores, as palavras de Samuel são esclarecedoras:

Como entusiasmo pedagógico, e depois como prática acadêmica, a História Social deriva sua vitalidade do seu caráter de oposição. Orgulha-se de preocupar-se com a 'vida real' ao invés de abstrações, com as pessoas 'comuns' ao invés das elites privilegiadas, com as coisas cotidianas ao invés dos eventos sensacionais [tradução livre]. ${ }^{6}$

Uma História Social "iluminada pela experiência dos de baixo", mas que procura sair do empirismo, formulando e defendendo a história de maneira sedutora, principalmente para aqueles que vivem num país profundamente desigual, sempre à espera da tão falada "repartição do bolo".7

É importante lembrar que a empatia para com as "pessoas comuns" (principalmente os trabalhadores) associa-se intrinsecamente com um tratamento mais crítico das fontes. Se antes o pretexto para reforçar a marginalização de elementos populares encontrava-se nas fontes, costumeiramente produzidas pelas classes sociais mais abastadas, agora é nela que o historiador social encontra a possibilidade de levantar o véu do esquecimento mediante métodos e problematizações. Por isso, Thompson considera o diálogo (em termos bem definidos) com a Antropologia e a Filosofia tão benéfico, pois estas oferecem recursos para se abordar velhas fontes sob uma nova ótica. ${ }^{8}$

Mas, e quanto ao Amazonas? Remetendo-se à sua experiência sobre pesquisadora dos seringais amazônicos, Barbara Weinstein reconhece que certo descaso com a preservação histórica aliada ao clima úmido tem dificultado o trabalho do historiador. Dificultado, não impossibilitado. A brasilianista enxerga duas alternativas possíveis: realizar o que Walter Benjamin chamou de "leitura a contra pelo", efetuando uma reinterpretação dos documentos oficiais e impressos

5 Tuxaua (chefe) dos Manaós, Ajuricaba desafiou o poder da coroa portuguesa na Amazônia ao se aliar com os holandeses que vinham das Guianas, utilizando suas armas para atacar algumas guarnições e aldeias ao longo do rio Negro. Em 1727, após dura batalha, ele foi preso pelos portugueses que o enviaram a Belém. Antes de chegar à capital do Grão-Pará e Maranhão, o líder indígena acorrentado, segundo as crônicas, teria se atirado nas águas do Amazonas, suicidando-se.

6 SAMUEL, Raphael. "O que é a História Social?" Revista História Social, Valência, n. 10, Instituto de História Social/ UNED, p. 135, 1991.

7 GOMES, Flávio dos Santos; NEGRO, Antônio Luigi. "Além de senzalas e fábricas: uma história social do trabalho". Tempo Social, São Paulo, n. 18, v. 1, p. 233-234, jun. 2006.

8 THOMPSON, Edward Palmer. "Folclore, Antropologia e História Social". In: ingleses e outros artigos. Campinas: UNICAMP, 2002, p. 252. . As peculiaridades dos 
em busca dos subsumidos; e fazer uso da história oral, colhendo depoimentos das pessoas. ${ }^{9}$

Tais caminhos se apresentam como aconselháveis principalmente para aqueles curiosos com a sombra que paira sobre períodos recentes da nossa história. Ora, para Luís Balkar Peixoto Pinheiro, são os anos posteriores ao ocaso da borracha que configuram ainda hoje como uma fronteira pouco explorada pelos historiadores do trabalho..$^{10}$ Felizmente muitos têm ouvido seu apelo, lançandose à procura de maiores informações sobre as lutas sociais e as experiências de homens e mulheres que viveram entre as décadas de 1910 até os nossos dias.

Gostaria aqui de contribuir, ainda que minimamente, com essa tendência animadora (embora se desenvolva num contexto preocupante de risco de flexibilização das garantias trabalhistas no atual governo) chamando a atenção para mais uma fonte tão crucial quanto as demais citadas: a Literatura. Sim, ela que foi proscrita pelos arautos da "história objetiva e imparcial", mas reabilitada pelas correntes historiográficas posteriores. Déa Fenelon assinala que os precursores da nova História Social já demonstravam o seu intento em trabalhar com ela em seus livros: Thompson com sua biografia de um poeta, William Morris - Romantic to Revolutionary (1955), Richard Hoggart com The Uses of Literacy (1957) e Raymond Williams com The Long Revolution (1961). ${ }^{11}$

Mas como as experiências podem ser captadas através das lentes da literatura? Em primeiro lugar, é importante reconhecer que ela interpreta a realidade de forma bem peculiar por conta de sua dupla condição, como alerta Antônio Cândido:

Como conjunto de obras de arte a literatura se caracteriza por essa liberdade extraordinária que transcende nossas servidões. Mas na medida em que é um sistema de produtos que são também instrumentos de comunicação entre os homens, possui tantas ligações com a vida social, que vale a pena estudar a correspondência e a interação entre ambas. ${ }^{12}$

Pierre Bourdieu tentou demonstrar por meio de suas radiografias sociológicas da intelectualidade francesa que a literatura é mais um cristal, refratando a luz em mil cores, que um espelho, que reproduz fielmente o que lhe é confrontado. ${ }^{13}$

Procurando contemplar pressões sociais e artísticas, Bourdieu propôs uma visão da literatura enquanto campo, onde agentes concorrem entre si por postos privilegiados. Suas obras expressam sentimentos e ideias, mas também são "cartas de intenção" aos demais colegas.

Nestas condições, quase todas as obras trazem a marca do sistema de posições em relação às quais se define sua originalidade, e contêm indicações acerca do modo com que o autor pensou a novidade de seu empreendimento, ou seja, daquilo que o distinguia, em seu entender, de seus contemporâneos e de seus antecessores. ${ }^{14}$

9 WEINSTEIN, Barbara. "Experiência de pesquisa numa região periférica: a Amazônia". História, Ciências e Saúde, Rio de Janeiro, vol. 9, n. 2, p. 267-270, maio-ago. 2002.

10 PINHEIRO, Luís Balkar Sá Peixoto. "Mundos do trabalho em Manaus, 1920-1945: uma proposta de investigação". In: XXIV SIMPÓSIO NACIONAL DE HISTÓRIA - ANPUH, 2007, São Leopoldo/RS. Anais do XXIV Simpósio Nacional de História. São Leopoldo: Unisinos, 2007, p. 7. (Anais eletrônicos).

11 FENELON, Déa Ribeiro. "Cultura e História Social: historiografia e pesquisa". Projeto História, São Paulo, n. 10, dez. 1993, p. 89.

12 CÂNDIDO, Antônio. A educação pela noite. São Paulo: Editora Ática, 1988, p. 163.

13 BOURDIEU, Pierre. Razões práticas: sobre a teoria da ação. Campinas: Papirus Editora, 1996, p. 61.

14 BOURDIEU, Pierre. "O mercado de bens simbólicos". In: . A economia das trocas simbólicas. Trad. 
A teoria de Bourdieu pode ser proveitosa para o presente estudo, sobretudo se é almejado identificar o vínculo entre o trabalho e a literatura nas personagens e situações construídas por Antísthenes Pinto. O pesquisador francês sempre enfatizou a importância das regras não escritas da arte, principalmente da literatura.

O leitor bem informado há de estranhar que um artigo que se proponha falar sobre a nova História Social, fortemente inspirada no marxismo, utilize um sociólogo de filiação weberiana como referencial teórico. Principalmente se levar em consideração que o próprio defendia que sua teoria exigia "uma série de rupturas" com o marxismo. No entanto, as rupturas dizem respeito à "tendência para privilegiar as substâncias (...) em detrimento das relações". ${ }^{15}$ Ou seja, Bourdieu insurgiu contra a presunção de reduzir as classes sociais a uma categoria fixa e homogênea, característica da corrente hegemônica do marxismo francês liderada por Louis Althusser.

Eis, portanto, um aspecto que aproxima Bourdieu de Thompson, uma vez que este também atacou o estruturalismo de Althusser, reivindicando uma atenção maior à experiência. ${ }^{16}$ Outro ponto em comum é o valor que os autores concedem à percepção dos sujeitos históricos: para o primeiro, a distinção social é essencial para que os agentes sociais definam suas estratégias; enquanto para o segundo, ela fornece uma identidade necessária para que no decorrer das lutas sociais se transforme em consciência de classe. Afinal, para Thompson "a classe acontece quando alguns homens (...) sentem e articulam a identidade de seus interesses entre si, e contra outros homens cujos interesses diferem (e geralmente se opõem) dos seus"..$^{17}$

Contudo, apontar similaridades nos seus intentos não elimina as diferenças de suas perspectivas. Se Thompson privilegia a experiência, Bourdieu por vezes parece engessá-la em nome das normas sociais adquiridas e interiorizadas (o habitus) nos agentes sociais, como aponta Michel de Certeau. ${ }^{18}$ Outra grande crítica a Bourdieu reside na sua instrumentalização dos valores. Assim, não existe ato desinteressado nem julgamento moral que não almeje encobrir interesses sociais. Nesse ponto, o sociólogo Jessé Souza assinala que:

O que Bourdieu nega ao relativizar todo juízo moral e mostrar seu caráter meramente instrumental é o fato de que os indivíduos, as classes e as sociedades 'aprendem moralmente' ainda que a custo de sofrimentos inauditos, guerras e muito sangue derramado. Existe, mesmo inarticuladamente, uma noção de 'boa vida' e 'virtude' subjacente a todas as nossas ações, embora não sejamos conscientes dela quase nunca. ${ }^{19}$

Ao valorizar a experiência dos sujeitos históricos, Thompson aborda o aprendizado moral, pois considera que a produção tanto quanto a tradição

Sérgio Miceli. 6. ed. São Paulo: Perspectiva, 2009, p. 112.

15 BOURDIEU, Pierre. "Espaço social e a gênese das classes". In: Poder simbólico. Trad. Fernando Thomaz. 14. ed. Rio de Janeiro: Bertrand Brasil, 2010, p. 133.

16 THOMPSON, Edward Palmer. A miséria da teoria ou um planetário de erros. Trad. Waltensir Dutra. Rio de Janeiro: Paz e Terra, 1981, p. 229.

17 THOMPSON, Edward Palmer. A formação da classe operária inglesa: a árvore da liberdade. Trad. Denise Bottman. v. 1. Rio de Janeiro: Paz e Terra, 1997, p. 10.

18 CERTEAU, Michel de. A invenção do cotidiano: artes de fazer. 17. ed. Trad. Eprahim Ferreira Alves. Petrópolis: Vozes, 2011, p. 119.

19 SOUZA, Jessé. A tolice da inteligência brasileira ou como o país se deixa manipular pela elite. São Paulo: LeYa, 2015, p. 161. 
intelectual, o trabalho tanto quanto o universo moral orientam a ação dos sujeitos históricos. $^{20}$

Isso fica especialmente claro em duas oportunidades: na pesquisa sobre uma severa lei sobre o uso das florestas presente no livro Senhores e Caçadores e no estudo sobre os "motins da fome" incluso na obra Costumes em Comum. No primeiro caso, Thompson defende uma interpretação da lei não só como instrumento de dominação classista, mas como artefato cultural que também portava algum amplo valor moral universal.

\begin{abstract}
A maioria dos homens tem um forte senso de justiça, pelo menos em relação aos seus próprios interesses. Se a lei é manifestamente parcial e injusta, não vai mascarar nada, legitimar nada, contribuir em nada para a hegemonia de classe alguma. (...) E, ademais, não é frequentemente que se pode descartar uma ideologia dominante como mera hipocrisia; mesmo os dominantes têm necessidade de legitimar seu poder, moralizar suas funções, sentir-se úteis e justos. ${ }^{21}$
\end{abstract}

No entanto, existem normas morais que não necessariamente redundam em leis e não necessariamente se fundamentam numa visão universalista. É o que o historiador britânico demonstra quando aponta uma "noção legitimadora" orientando os "motins da fome" dos camponeses do século XVIII:

Isso, por sua vez, tinha como fundamento uma visão consistente tradicional das normas e obrigações sociais, das funções econômicas peculiares a vários grupos na comunidade, as quais, consideradas em conjunto, podemos dizer que constituem a economia moral dos pobres. 0 desrespeito a esses pressupostos morais, tanto quanto a privação real, era o motivo habitual para a ação direta. ${ }^{22}$

Thompson defende que a "economia moral" não era "política" no sentido contemporâneo, tampouco "apolítica", uma vez que os camponeses entendiam que uma definição de bem-estar comum estava em jogo.

O conceito de "economia moral" será tão caro à pesquisa quanto o conceito de "habitus", pois ambos conseguem demonstrar muito bem a relação entre a dimensão simbólica e material que rege a ação dos sujeitos históricos. Como aqui pretendo falar de um personagem que se move justamente no espaço intermediário entre a intelectualidade e o mundo do trabalho, parece mais adequado explorar a contribuição de dois grandes nomes que se dedicaram a elucidar a dinâmica dessas respectivas dimensões da sociedade: Bourdieu e Thompson.

\title{
O "grupo bem formado" e as "pessoas desimportantes"
}

Além do título, está estampada na capa de Os Agachados a classificação ambígua de "ficção reportagem". Não há maiores esclarecimentos sobre tal tipologia no

20 GOMES, Ângela de Castro. A invenção do trabalhismo. 3. ed. Rio de Janeiro: Editora da Fundação Getúlio Vargas, pp. 18-19.

21 THOMPSON, Edward Palmer. Senhores e Caçadores: A origem da Lei Negra. Trad. Denise Bottmann. Rio de Janeiro: Paz e Terra, 1987, p. 354.

22 THOMPSON, Edward Palmer. "A economia moral da multidão inglesa no século XVIII". In: Costumes em comum: estudos sobre a cultura popular tradicional. São Paulo: Companhia das Letras, 1998, p. 152. 
prefácio: Trata-se de algo sugerido pelo próprio autor, na esteira do jornalismo literário, ou uma categoria criada pelos organizadores do concurso cultural da Superintendência da Zona Franca do Amazonas (Suframa)? Ainda não fui capaz de responder tal pergunta.

No decorrer da trama, os nomes de lugares e pessoas reais surgem em negrito como que apontando didaticamente os pontos não ficcionais do livro. Dentre os lugares, o destaque maior são os botecos: Alex Bar, Katkero, bar do Armando e os pequenos botecos da rua Luiz Antony. Há ainda a menção a um precário bordel instalado próximo à ponte do São Raimundo, cenário do misterioso ato final. Com exceção do bordel, todos os lugares citados pertencem à zona central da cidade.

Quanto aos personagens, alguns são apenas mencionados, como os candidatos a governador do Amazonas no pleito de 1982: Josué Cláudio Souza e Gilberto Mestrinho. Outros simplesmente dão o ar da graça nos botecos, como o senador Evandro Carreira e o artista plástico Afrânio de Castro. Sob o apelido de Troglodita, um dos muitos a ele atribuídos pelos amigos, Castro interrompe a conversa de todos no bar para apresentar seu novo quadro, mas diante da indiferença dos boêmios reage com hostilidade. ${ }^{23}$ No caso de Carreira, a aparição conota a "naturalidade de homem identificado com seu povo", como se o status político não tivesse corrompido sua origem humilde. ${ }^{24}$

Os Agachados possui uma linguagem sóbria beirando a forma coloquial, em nada lembrando os poemas neoconcretos de Antísthenes Pinto. Apesar de Rinaldo ser o protagonista, há capítulos que seguem o fluxo de consciência de personagens secundários. A narrativa intercala momentos de confraternização nos bares com a profunda solidão de Rinaldo.

O realismo dá a tônica do romance, mas há um veio onírico latente no enredo no tocante à figura do amigo francês de Rinaldo. Girard perdera a família no Vietnã e se entregara à boemia em Manaus, enquanto trabalhava como técnico em borracha para uma usina de beneficiamento do produto. No momento em que a história se desenrola, Girard já havia falecido há seis meses, mas Rinaldo o vê em todos os lugares. Girard seria fruto dos delírios etílicos de Rinaldo ou realmente uma presença sobrenatural? O narrador reitera a questão ao longo das páginas até resolvê-la de forma emblemática no final do livro.

Os amigos de copo de Rinaldo estranham sua mudança de comportamento: "Que sujeito educado, fino, você precisava ver. (...) Hoje toma cada porre, insulta os próprios amigos (...)". ${ }^{25}$ Recebem com surpresa e dúvida a notícia de que ele matara a tiros um homem que subiu no muro de sua casa, sem saber que para Rinaldo tratava-se de mais um dos "sósias" assustadores de Girard.

Os comentários sobre Rinaldo, jornalista e funcionário da Prefeitura de Manaus, sempre exploram a contradição entre sua condição social e sua bagagem cultural, como é manifesto no fragmento abaixo:

Mas, palavra, eu preferia ser um sujeito assim como Rinaldo, como Cruz; são pobres mesmo, mas quando entram em qualquer ambiente merecem toda a consideração, toda simpatia, todo o respeito. ${ }^{26}$

23 PINTO, Antísthenes. Os agachados. Manaus: Casa Editora Madrugada/SUFRAMA, 1985, p. 65.

24 PINTO. Os agachados, p. 76.

25 PINTO. Os agachados, p. 24.

26 PINTO. Os agachados, p. 47. 
A mesma ambiguidade repousa na representação de Afrânio de Castro: à primeira vista, uma "figura grotesca de homem", mas que se revela o "melhor artista da terra" em suas sofisticadas e profundas obras apresentadas nos bares e botecos em primeira mão. ${ }^{27}$ Trata-se de uma dualidade que será analisada mais detidamente no próximo segmento.

No circuito de amizades de Rinaldo encontram-se juízes e advogados (como Zeferino e Tomoso), empresários (como Ariosto e Som-Som), funcionários públicos (como Firmino) e trabalhadores cuja ocupação nem sempre fica muito clara (como Serra Grande, Jarrão e Zóio). Apesar de acompanhar seus porres pela cidade, a maior parte da narrativa concentra-se no fictício bar do Espinhel. Sobre seus frequentadores, o protagonista esclarece:

\begin{abstract}
Advogados, empresários, magistrados da ativa e aposentados, poetas, cantores, músicos, gerentes de bancos, jornalistas, altos funcionários do governo, políticos. Um grupo bem formado. No início, assim diziam, era só gente importante, de bem. Depois apareceram umas pessoas desimportantes, mas que tinham algum pé-de-meia, geralmente conhecidas dos figurões. Gostaram do bar e arriaram ferros. No geral, porém, todos se entendem. De quando em vez uma fisgada aqui, um desentendimento ali. O bar começou a ganhar fama. ${ }^{28}$
\end{abstract}

A história foca no grupo inicial de frequentadores: homens de meia-idade que pertencem à elite administrativa e econômica local. Rinaldo pertence a esse grupo como uma espécie de agregado, sendo aceito mais pela sua imagem pública que pelas suas credenciais. Assolado pelo fantasma de Girard e pelo peso do tempo, Rinaldo já demonstra estar cansado em continuar fazendo o jogo da aprovação social.

Há uma percepção comum a todos os membros do grupo de que o bar do Espinhel já não é mais fiel à sua clientela original. $\mathrm{O}$ assunto é recorrente e geralmente é posto do seguinte modo:

\footnotetext{
- Rapaz - disse Tomoso para Ariosto - como eu estava te dizendo, naquele bar tem que haver mais respeito. Afinal de contas, fomos praticamente nós que o inauguramos.

- Mas o que podemos fazer - secundou Ariosto - se o bar é público?

- Aí é que está o teu engano - ponderou Tomoso -, quem é que o sustenta realmente?29
}

Assim, se por um lado o romance que se propõe uma descrição artística da boemia amazonense, limitando-se ao recorte de uma pequena camada de frequentadores de bares do centro de Manaus, por outro ele também aponta para o processo de redemocratização do Brasil que se consumaria oficialmente com as eleições para presidente da República, em 1985.

Não há cenas de explícita manifestação política contrária ao regime militar, mas referências ligeiras a políticos contrários a ele, como Evandro Carreira e Gilberto Mestrinho, membros do Partido do Movimento Democrático Brasileiro (PMDB). Carreira defendia no Senado os problemas gerados pelos projetos desenvolvimentistas na Amazônia, enquanto Mestrinho concorria às primeiras

\footnotetext{
27 PINTO. Os agachados, p. 64-65.

28 PINTO. Os agachados, p. 25.

29 PINTO. Os agachados, p. 22.
} 
eleições diretas para governador evocando seu passado de líder trabalhista antes do golpe de $1964 .{ }^{30}$

A narrativa confere um olhar mais positivo a Carreira, demonstrando o jubileu popular nas ruas diante de sua presença, mas não oferece um discurso político mais claro. A maior alusão à redemocratização talvez esteja encerrada na abertura do bar do Espinhel a novos clientes, pessoas "desimportantes". Esses novos personagens que entram em cena começam a definir a atmosfera do lugar, a contragosto dos frequentadores iniciais que planejam uma manobra para recuperar seu posto.

A desconfiança de Pinto quanto ao processo de redemocratização, tendo em vista a força dos "grupos bem formados", se fundamentaria na reprovação feita pelo Congresso da emenda constitucional proposta por Dante de Oliveira, que defendia a volta das eleições diretas para a Presidência da República em 1985? É bem possível que o autor tenha compartilhado da mesma frustração que tomou conta da sociedade civil e dos movimentos sociais que aspiravam o retorno ao Estado Democrático de Direito.

\section{Aninhado num escape?}

Dois pontos em Os Agachados merecem uma atenção maior: a representação da boemia e a representação do autodidata. São elementos que estão relacionados não só com a história da intelectualidade e dos trabalhadores amazonenses como com a própria experiência do autor.

Em primeiro lugar, a boemia descrita por Antísthenes Pinto se configura um espaço aberto para pessoas de diferentes países, classes sociais e credos. O negro Serra Grande pode falar com o doutor Zeferino sem obedecer ao protocolo. $\mathrm{O}$ francês Girard pode contar sua história a Rinaldo, assim como ele conta a sua ao auditor de uma empresa multinacional. As conversas também são sobre os mais variados assuntos, desde fofocas até discussões mais metafísicas. Mesmo no bar do Espinhel, após o estranhamento com a mudança do perfil do público, "todos se entendem".

O "sal do cotidiano", nesse sentido, representa uma saída, um universo alternativo onde as barreiras sociais não são destruídas, mas mitigadas. $\mathrm{O}$ álcool nivelando todos os homens pela inescapável necessidade do lazer. Trata-se de uma visão apologética da boemia.

Mas a boemia também tem uma forte clivagem social que não pode ser menosprezada. Seu usuário "autorizado" é o dândi, que a recobre de metafísica, enquanto os praticantes pertencentes a estratos mais humildes são criminalizados. Como se o potencial degenerativo do álcool despertasse o que há de mais primitivo e rudimentar nos mais pobres. Esse discurso disciplinar acompanhou também o mundo do trabalho amazonense, embora não acarretasse no fim do consumo do copo de cana que revitaliza o trabalhador e da pinga que amortece a dureza dos ofícios pesados.

Após exaustiva pesquisa quantitativa sobre a criminalidade urbana em Manaus entre 1905 e 1915, Paula Dantas conclui que:

30 FARIAS, Orlando. A dança dos botos e outros mamíferos do poder. Manaus: Editora Valer, 2010, p. 48; TORRES, Iraíldes Caldas. Arquitetura do poder: memória de Gilberto Mestrinho. Manaus: Editora da Universidade Federal do Amazonas, 2009, p. 208. 
O fato de a maior parte dos crimes registrados mencionarem o abuso de bebida alcóolica nos dias de semana, após o expediente e nos dias de folga, sugere a importância dos bares enquanto locais de sociabilidade para essa camada da população que não tinha acesso aos salões dos Clubs geralmente frequentados pelas elites, assim como revela o esforço das elites para controlar tanto os ambientes quanto seus frequentadores. ${ }^{31}$

A despeito de todo o discurso disciplinar veiculado na imprensa e toda a legislação dedicada a conter costumes "incivilizados" da classe trabalhadora urbana que ajudou a constituir Manaus enquanto a Paris dos Trópicos na virada do século $\mathrm{XX}$, boemia e trabalho não eram dimensões diametralmente opostas, mas complementares.

Mas em Os Agachados, a boemia também adquire outros significados. Em dado momento, Rinaldo aconselha dois jovens artistas que escrevem obras engajadas a atentar para a fronteira entre o cotidiano e a literatura:

Os temas que vocês abordam, tanto um como o outro, no conto e na poesia, são do cotidiano e merecem a minha atenção. Mas ocorre que literatura é coisa muito mais séria, muito mais profunda. É necessário que vocês busquem com urgência o lado estético, que é essencial ao labor literário e artístico. Uma narrativa, por exemplo, que deixe este aspecto de lado, poderá tomar ares jornalísticos, sociológicos, históricos, mas nunca criativos, vocês percebem?32

Rinaldo nunca define bem o que seria esse "lado estético". Mas em momento anterior, conversando com um visitante que classifica como intelectuais os frequentadores do bar, o protagonista do romance alega que a boemia para o criador está ligada a armazenar emoções e não a atender necessidades, como fazem seus colegas. ${ }^{33}$

O sal do cotidiano converte-se então em matéria-prima e, se não for superado pela técnica artística, em prisão para o intelectual. Segundo Walter Benjamin, o risco dos "lampejos de sacralização" é garantir a manutenção da distância entre o autor e o trabalhador, impedindo que laços de solidariedade duradouros sejam forjados entre eles. ${ }^{34}$ Afinal, o produtor cultural nas sociedades contemporâneas também é um trabalhador.

Para Bourdieu, a boemia também foi um investimento intelectual para artistas que buscavam adquirir uma legitimidade alternativa, aquela das instituições literárias, que estavam vedadas a eles. ${ }^{35}$ Pertencer a uma realidade mais vívida, e por isso suja, foi encarada como trunfo. O selo da "arte maldita/moderna" é cunhado em tais termos na França.

No Amazonas, em 1954, um grupo de jovens artistas proclamou seu intento de realizar uma arte mais ligada à realidade regional, numa clara provocação aos rumos conservadores da Academia Amazonense de Letras. Para demonstrar seu lado lúdico e o compromisso com o chão cotidiano da arte, nomearam o

31 DANTAS, Paula. "Desordem em progresso: crime e criminalidade em Manaus (1905-1915)". (Dissertação de mestrado em História, Universidade Federal do Amazonas, 2014), p. 74.

32 PINTO. Os agachados, p. 71.

33 PINTO. Os agachados, p. 69.

34 BENJAMIN, Walter. "O autor como produtor". In: Paulo: Ática, 1985, p. 197.

35 BOURDIEU, Pierre. "A institucionalização da anomia". In: Thomaz. 14. ed. Rio de Janeiro: Bertrand Brasil, 2010, p. 278. Obras escolhidas. Flávio R. Kothe (org.). São Poder simbólico. Trad. Fernando 
movimento de Clube da Madrugada e fizeram da Praça da Polícia, para onde afluíam depois de passar pelos bares, como sua sede. ${ }^{36}$ Inspiravam-se nos autores boêmios franceses, mas apenas isso não basta para classificá-los como os representantes amazonenses de Rimbaud e Baudelaire. ${ }^{37}$

Apesar da heterogeneidade do grupo, o grosso de sua produção procura definir uma identidade regional, escudando-se em alguns momentos no Romantismo e em outros no Modernismo. Portanto, a defesa da boemia entre eles parece estar mais atrelada com a "desaristocratização" que os modernistas promoveram numa crítica aos ditames da literatura brasileira antes de $1930 .^{38}$

Parte desse esforço estava relacionada inclusive com a denúncia social da condição precária de trabalhadores amazonenses, principalmente aqueles do interior do estado. Nos contos de Arthur Engrácio, principalmente aqueles arrolados no seu livro de estreia, Histórias de Submundo (1960), desfilam seringueiros, pescadores e lavradores ribeirinhos. No conto Pescadores, a descrição da dinâmica do extrativismo justifica a opção do protagonista pelo arriscado ofício de arpoar jacarés na escuridão da noite:

O lago, apesar de distante e explorado, ainda oferecia oportunidade para quem não fosse cabra morredor. Não interessava mais borracha, balata, caucho. Para quê? Patrão sempre ganancioso a lhes roubar no preço, no peso, em tudo. Fim de fabrico, pensava em comprar uma calça, cadê dinheiro? ${ }^{39}$

Mas Engrácio, que nasceu em Manicoré, às margens do rio Madeira, não se ocupou apenas do elenco ribeirinho, mas também dos desvalidos e batalhadores no meio urbano. Num dos mais emblemáticos contos de "submundo", o Cão, um carvoeiro que possui apenas um cachorro como amigo interrompe seu trabalho para um descanso do qual nunca despertará.

No que se refere às lutas sindicais, o período que coincide com os dez primeiros anos do Clube da Madrugada é fértil de paralisações gerais e greves, muitas delas gestadas nas portas das fábricas e oficinas. A Casa do Trabalhador do Amazonas, criada para abrigar entidades sindicais (bem ao gosto do corporativismo que caracterizou o Estado Novo) em 1947, foi, nas palavras do gráfico Aviz Valente, "palco e cenário de muitas tertúlias e duelos verbais", participando ativamente da campanha O Petróleo é Nosso em meados dos anos 50 e da defesa das reformas de base pelo presidente João Goulart entre $1962 \mathrm{e}$ $1963 . .^{40}$

Surpreendidos pelo golpe de 1964, tanto quanto os líderes sindicais, os clubistas (ou madrugadores) figuraram como suspeitos de subversão, principalmente por preconizarem uma arte participativa. Entre os anos 50 e 60, instruir o povo para combater o imperialismo internacional tornou-se uma missão dos intelectuais brasileiros, inspirados na pauta dos movimentos de esquerda. ${ }^{41}$ No interior do clube, os escritores Luiz Ruas e Francisco Vasconcelos e o músico Pedro

36 TUFIC, Jorge. Clube da Madrugada: 30 anos. Manaus: Imprensa Oficial do Estado do Amazonas, 1984, p. 28.

37 FARIAS, Elson. Memórias literárias. Manaus: Editora Valer/Governo do Estado do Amazonas/ Uninorte, 2006, p. 67.

38 CÂNDIDO. A educação pela noite, p. 195.

39 ENGRÁCIO, Arthur. Histórias de Submundo. 2. ed. Manaus: Editora Valer/ Governo do Estado do Amazonas/ Uninorte, 2005, p. 55.

40 VALENTE, Aviz. Confederação Geral dos Trabalhadores do Amazonas: Antecedentes e protagonistas. Manaus: Travessia, 2005, p. 61.

41 ORTIZ, Renato. Cultura brasileira e identidade nacional. São Paulo: Brasiliense, 2010, pp. 74-76. 
Amorim eram publicamente simpáticos ao comunismo e por isso amargaram um tempo entre o cárcere e os interrogatórios.

Independente do espectro ideológico do movimento (que era multifacetado, acolhendo de comunistas a monarquistas), os eventos culturais e o suplemento literário mantido nas páginas de $O$ Jornal angariaram uma visibilidade notável para o clube de forma que alguns de seus membros mais proeminentes são convidados a integrar gabinetes do governo e as fileiras da Academia Amazonense de Letras. Para Jorge Tufic, cisões internas motivadas por essa "institucionalização" acarretaram o fim do movimento em $1967.4^{42}$

Há um bom número de autodidatas no Clube da Madrugada: Artur Engrácio não concluiu o ensino secundário no Ginásio Amazonense; ${ }^{43}$ Jorge Tufic não se bacharelou, mas trabalhava no Ministério do Trabalho;44 Hemérito Cabrinha, carpinteiro e poeta, foi um grande entusiasta do movimento; 45 Afrânio de Castro estudou Belas Artes, mas foi chofer de praça e vendedor de geladeiras em São Paulo antes de retornar à sua cidade natal; ${ }^{46}$ Hanneman Bacellar não pode frequentar boas escolas, por mais que sua mãe, zeladora do Palácio Rio Branco, desejasse que o filho abandonasse o porão escuro do prédio em que viviam ela, ele e os irmãos. ${ }^{47}$ Tufic ainda elenca em crônicas esparsas aquelas pessoas sem títulos que não investiram e tampouco se consagraram como líderes do grupo, mas que na lide diária colaboraram intensamente com ele, como o auditor da polícia José Trindade e $\mathrm{o}$ indigente Malaquias. ${ }^{48}$

Antísthenes Pinto pertenceu ao Clube da Madrugada, atuando de forma limitada no seu desenvolvimento. Conforme o amigo Jorge Tufic, Pinto começou a trabalhar como auxiliar de farmácia e depois como vendedor de próteses. Mudouse para o Rio de Janeiro; desdobrava-se então entre a função de escrivão de polícia e alguns "bicos"49. Retornou à sua cidade natal em 1970, reconhecido por artigos que foram veiculados na imprensa do Rio de Janeiro. Foi nomeado diretor de Cultura e Promoções da Prefeitura de Manaus e logo depois superintendente cultural do Amazonas. ${ }^{\circ}$ Portanto, sua trajetória é marcada pela mobilidade, tanto empregatícia quanto espacial.

Algumas características, como a origem humilde, aproximam o autor do protagonista de Os Agachados. Rinaldo goza de prestígio, mas não se ilude: o bom tratamento para consigo é circunstancial. À mesma conclusão chega Ramiro, amigo de Rinaldo, que ascendeu socialmente vendendo terras: "Quando eu batia sola de sapato, dando um duro feladaputa (sic), ninguém me oferecia nada, ninguém olhava pra mim. Só eu sei do meu sofrimento do meu tempo de sapateiro". ${ }^{1}$ Rinaldo também dá a entender que já participou do Clube da Madrugada, assim como Afrânio de Castro e Evandro Carreira.

Rinaldo é uma figura melancólica que enxerga o comportamento dos seus colegas, do "grupo bem formado" ou das "pessoas desimportantes", com

42 TUFIC, Jorge. O sonho de Tibério. Manaus: Academia Amazonense de Letras, 2011, p. 137.

43 TUFIC. O sonho de Tibério, p. 21-22.

44 TUFIC. O sonho de Tibério, p. 34-35.

45 SILVA, Alencar. Quadros da moderna poesia amazonense. Manaus: Editora Valer, 2011, p. 17.

46 ENGRÁCIO, Arthur. Afrânio Castro: o quadro sem retoque. Manaus: Governo do Estado do Amazonas, 1992, p. 24.

47 MICHILES, Aurélio. E tu me amas? Revista Somanlu, Manaus, ano 5, n. 1, p. 13, jan.jun., 2005.

48 TUFIC. O sonho de Tibério, p. 118-119; TUFIC, Jorge. Tio José. Manaus: Casa Editora Madrugada, 1975, p. 16-19.

49 TUFIC, Jorge. "Apresentação". In: PINTO, Antísthenes. Poesia reunida. Manaus: Puxirum, 1987, p. XVIII.

50 ENGRÁCIO. Poetas e prosadores do Amazonas contemporâneo, p. 7.

51 PINTO. Os agachados, p. 35. 
cinismo, mas nem por isso é indiferente às desigualdades sociais que assolam Manaus. A criminalidade grassa em quase todos os bairros e muitos empresários cogitam entrar no agora extremamente rentável negócio da prostituição: assim, no romance a boemia parece refletir a decadência da cidade.

Trata-se de uma Manaus pós-instalação da Zona Franca de Manaus que já sente os efeitos do êxodo rural. A cidade cresceu, mas os serviços urbanos não foram estendidos a todos. O glorioso futuro de prosperidade econômica, apregoado tanto pelos políticos locais quanto pelos militares no comando do país, em Os Agachados é apenas uma piada.

No último capítulo, quando Rinaldo desce o pequeno labirinto de degraus ao lado da ponte do São Raimundo, ele revê o cenário de miséria dos moradores. Fica surpreso com as mulheres quebrando pedras na beira do rio: "Em pleno século das máquinas sofisticadas, essas pobres mulheres e crianças quebram pedras para sobreviver (...)".52 Rinaldo é assombrado pela imagem, mas tudo que pode fazer por elas é um poema:

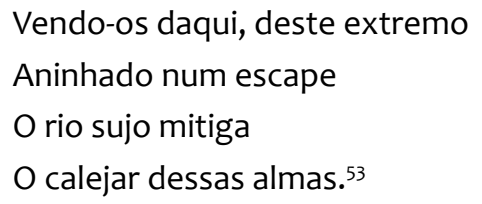

Da posição em que se encontra Rinaldo, a paisagem desoladora parece eclipsar o sofrimento das mulheres e crianças. Mas Rinaldo é franco: ele esclarece que está protegido, confortavelmente instalado num escape. O seu "ninho" pode ser tanto o bordel de onde avista a cena quanto sua posição social. O intelectual autodidata é representado então como alguém dilacerado pelas exigências de dois mundos e que exatamente por isso, ao fim e ao cabo, tem um poder extremamente limitado.

Mas, analisando a cultura radical que se configurou nas vilas e aldeias britânicas, Thompson apontou o papel mobilizador dos autodidatas, "(...) diaristas, artesãos, lojistas, escreventes e mestres-escolas [que] punham-se a aprender por conta própria, individualmente ou em grupo".54 É inegável o potencial explosivo dessa camada intermediária, entre uma intelectualidade sedimentada enquanto tal e o mundo do trabalho tradicional; mas será que ela foi tão explosiva assim em Manaus?

Numerosas pesquisas demonstram que a década de 1980 em Manaus foi campo de batalha de diversas entidades e movimentos sociais que passaram a se organizar e se posicionar contra a força do capitalismo internacional e do regime militar. Milton Reis Filho enumera algumas delas que mobilizaram a cidade entre 1983 e 1985: a Pastoral Operária, o Partido dos Trabalhadores, a Associação dos Docentes da Universidade do Amazonas e o Sindicato dos Trabalhadores Metalúrgicos da Zona Franca de Manaus. ${ }^{55}$

Em agosto de 1985, os operários do Polo Industrial de Manaus (PIM), situado estrategicamente numa região afastada do centro da capital amazonense, realizaram uma paralisação bem coordenada contra as rígidas medidas disciplinares e o baixo salário das empresas. Numa fábrica, BSR, as trabalhadoras iniciaram

52 PINTO. Os agachados, p. 95.

53 PINTO. Os agachados.

54 THOMPSON. A formação da classe operária inglesa, p. 304.

55 REIS FILHO, Milton Melo dos. A saga dos operários em Manaus: 1980. Manaus: EDUA, 2013, p. 144-145. 
uma paralisação, mas foram expulsas do prédio e deixadas lá sem água e sem alimentação. Uma operária de outra fábrica, que prefere se identificar como H.A., informou a Milton Reis Filho que:

Então a gente fazia o seguinte, por exemplo, pegávamos o saco plástico na linha de montagem. Um sujeito não comia o arroz, outro não comia o feijão, o outro não comia a carne toda, para a gente juntar aquela alimentação e levar para as companheiras que estavam paradas lá na outra fábrica, que não tinham uma organização igual a nossa, e não havia nenhum dirigente para enfrentar o patrão. ${ }^{56}$

A solidariedade liga colegas de trabalho principalmente por conta da percepção de que estavam enfrentando uma situação tremendamente injusta. Os grevistas conviviam com uma diversidade ideológica admirável (de influências do trotskismo a pastoral católica), mas é evidente, principalmente pela pesquisa de Reis Filho, que eles também compartilhavam um senso de justiça, uma "noção legitimadora", que os unia mais e mais durante sua luta.

Em Os Agachados não figuram operários, mas empresários e gerentes de firmas exportadoras. Nas histórias sobre sua ascensão social repentina bem como nas considerações sobre seu status fica patente o julgamento moral do autor: o arrivismo não carrega a dignidade do trabalho, muito menos cultiva a solidariedade. De um lado, o imobilismo das tradicionais elites locais, do outro, o oportunismo de grupos sociais mais novos.

Rinaldo e Ramiro trabalharam duro e ajudaram muitas pessoas em contraposição a outros personagens da galeria do bar do Espinhel, que valorizam mais o enriquecimento que o conhecimento, o trabalho e a amizade. É uma moral primária, mas que era compartilhada por muitos moradores de Manaus. Não deixa de dizer respeito a uma noção de bem-estar comum ameaçada pelo consumismo e o individualismo desenfreado que passou a vigorar na cidade após a instalação da Zona Franca em 1967.

Assim, Antísthenes Pinto não exorta os trabalhadores à luta em seu livro, mas estimula o inconformismo ao apresentar com tintas fortes uma cidade rica, mas paradoxalmente precária graças a uma elite dirigente inepta, que, perseguindo a ascensão fácil, transformou Manaus em uma refém do capitalismo internacional. Trata-se de uma ação muito menos direta, mas coerente com a visão que o autor tem do papel do intelectual e do autodidata.

\section{Considerações finais}

Em Os Agachados, a questão do sal do cotidiano se relaciona profundamente com as escolhas do autor: a temática, o estilo narrativo e até a construção dos personagens. A boemia em Antísthenes Pinto revela de forma emblemática os descaminhos da história recente do Amazonas e as ambiguidades que cercam a figura do intelectual, amparando-se inclusive numa "noção legitimadora" do trabalho. Ao construir sua narrativa de tal maneira, Pinto estaria apostando em mais um investimento intelectual, segundo a ótica de Bourdieu, capaz de garantir uma posição privilegiada como romancista e artista popular ou realmente incentivando a revolta por meio do apelo a uma "economia moral" popular,

56 REIS FILHO. A saga dos operários em Manaus, p. 163. 
para usar a expressão thompsoniana, retornando assim aos valores que adquiriu em sua trajetória anterior como trabalhador? A princípio, nada impede que ele tenha conjugado ambas as atitudes pelas suas respectivas razões. Contudo, mensurar quão bem sucedido ele foi nessa empreitada é uma questão para outra oportunidade.

Enviado: 20/06/2016

Aprovado: 01/03/2017 
